\title{
The Madhubani Metamorphosis: The Intersection of Art, Ritual and Gender Roles
}

\author{
Aqsa Ashraf and Shreyasi Jha
}

\begin{abstract}
The Indian subcontinent has seen the emergence and extinction of multiple populaces, but the remnants of their existence have been reflected in the creations that they left behind, a form of which is visual-art. In its embryonic stages, visual-art was not individualistic, but rather an echo of the society put into one work of art, a portrayal of native lands and cultures. Madhubani painting, holding similar characteristics, was born in Mithila, home to four of the six Schools of Philosophy of ancient India. Mithila's rich classical culture intermingling with the vivid folk traditions, led to the creation of multiple cultural rituals, out of which Madhubani painting is one. Madhubani painting started as a form of visual-art on an earthen surface, often coated with cow-dung called aripan, developing into a mural style of painting and was eventually commercialized, when paper and fabric was introduced to make the art portable and sellable. This form of art is a highly gendered space, mostly involving women, charged with ritualistic motifs used in the celebration of events, such as wedding rituals, harvests, chaurchan, kojagara and full moons, among others. From the 1970s, the artform has become more commercialized and individualistic rather than community based. The medium of the painting has transgressed from using dyes procured from natural resources such as soot, harshringar flower, bamboo reeds, etc. to the usage of fine-liner pens and other modern stationary items. The contemporary artists are compelled to conform to the ever-changing eagerness for novelty by the market, changing the intrinsic nature of this artistic space. Through our paper, we aim to adopt an anthropological approach to analyze the transition of Madhubani painting to a commercialized artform, encapsulating the features of avant-gardism from the highly ritualistic, gendered and most importantly, a vernacular artform of the people of Mithila.
\end{abstract}

Index Terms-Madhubani painting, art history, anthropology, artistic transition, rituals, gender.

\section{INTRODUCTION}

Consumption and creation go hand in hand. Any creation is meant for consumption and does not develop or sustain in isolation. Likewise, when art is created, one of its main purposes is to be consumed by an audience. Art has a purpose and it is not merely aesthetical. Artists through courses of time have evolved from creating art as a form of reflection and expression to creating art that is a source of their livelihood. The art of aesthetic especially in today's world needs to be combined with the art of business in order to sustain as an artist. In the context of Madhubani painting, we have seen how it has developed from a very ritualistic, gendered, socially structured and most importantly personal

Manuscript received April 5, 2019; revised July 1, 2019.

Aqsa Ashraf and Shreyasi Jha are with the Gargi College, University of Delhi, India (e-mail: aqsaa.ashraf@gmail.com, shreyasiakhileshjha@gmail.com). space to a commercialized art-form, that encapsulates not only the characteristics that existed beforebut has expanded its boundaries and made it permeable. This expansion and permeability is not a single day or single act phenomenon. Decades carrying influence and need from changes in time, market space, mindsets and understandings have kept this art form ever changing, yet grounded with its roots in Maithil tradition. Breakthrough in terms of Madhubani/Mithila [1] Painting was brought in post the aftermath of the massive 1934 earthquake that happened in Mithila. This painting derives its name from Madhubani, a district in the Bihar province of India. Its other name Mithila is a cultural region spread along the borders of Nepal going down to the river Ganga.

William G. Archer, a young British ICS officer posted in Madhubani, wrote in great detail about his observations and understanding of "Maithil Painting", as he called it, when he visited the countryside of Madhubani immediately after the earthquake in the thirties of the twentieth century. Archer's work, which was published in Marg, was one of the earliest attempts at documenting the folk art of Madhubani, especially how the nature of its caste base affects the paintings [2]. However, his aim seems to limited to examining and documenting only. Two decades after Archer's documentation, Mithila was struck by a famine caused due to droughts in the late 1950s and early 1960s. Although seven rivers, among which are the Ganga, the Gandak, the Mahanadi and the Kosi meander through the plains of Mithila, agriculture in the region like the rest of India's northern plains, is dependent upon the Monsoon rains. The failure of monsoons had caused the drought, and villages like Jitwarpur in Mithila were among the ones most severely affected. Nevertheless, Maithil painting as a ritual was still the same as it had been when Archer had served in Mithila. However, India was no longer a colony of the British and the new state government was faced with a challenge to promote self-sufficiency in Mithila to cope with the lack of food resources by creating employment. Pupul Jayakar, a cultural activist, urged the government to provide art supplies to the women in Mithila to produce their paintings on paper and cloth in order to make them sellable. Scholars also credit Bhaskar Kulkarni, aide to Jayakar, who had been sent to Mithila to begin the commercialization of Maithil paintings, for his catalyst role creating employment during the famine. Kulkarni also brought some of the paintings to be shown at an exhibition in New Delhi, where their painters did not just find buyers but also national and international recognition [3]. Mr. Upendra Maharathi also played an important role in making Madhubani painting viable for competing in commercial spaces.

There are multiple folds within what the art scene of 
Madhubani painting is developing in present times. There is one section that consists of artists that can be considered as puritans, they follow ritualistic patterns, motifs and depictions; they take the traditionalist route and believe in preserving the fundamental form of art, they create art not for commercial purpose. The other section is more transgressed and fluid in nature, they try to incorporate novelty and not-so traditional influences into their art. Somewhere in the middle lies the majority, which tries to use traditional projections to cater to the market while incorporating modern amenities that help them to sustain on a commercial scale. Mithila painting is an old tradition, but a fairly new commodity in the market. Its artists are compelled to take on a transition to creating art fit for the needs of their buyers by expanding their creative boundaries, bringing in an aesthetic value and making their art permeable as a means of livelihood. At the same time, they have to encapsulate the same re-occurring motifs and as far as possible, conventional techniques, so as to not take out the "tradition" from traditional art in a modern market.

\section{Semantics of Madhubani Painting}

A typical Madhubani painting would traditionally have illustrations, depicting scenes from Ramayana. The region of Mithila has a poignant relationship with Sita, one of the main characters from Ramayana, she hailed from Mithila. What a region chooses to portray in a customary painting that is of the people, often reflects their emotional sensibilities and what they choose to include in their cultural heritage. Sita's story is painful, for Maithil people it is especially significant because she is considered as the daughter of their land. The story of her difficult marriage and then separation from Lord Ram lives on and thus, portrayal of her life including the rituals of their marriage ceremony are extremely popular in Mithila. Some popular paintings are of the birth of Sita, Girija Poojan, which is the worship of goddess Parvati, also known as Girija; Sita playing on the swings with her friends, the Dhanush Yagya, the Swayamvara where Sita chose Ram to be her husband, the Jayamala or exchange of garlands between Sita and Ram, the Nauka Vihar of Sita and Ram which is considered to be a way of being close to their devotees, and Dhanush Poojan - the worship of bow, etc. What is noteworthy is that some of these ceremonies and rituals are still prevalent and extremely important in Maithil weddings. When a painting is made for ritualistic purposes, motifs are carefully chosen, depending upon the occasion and on the artist's place in the varna system. A Maithil wedding is one of the most important ceremonies carried out in the region. The Kohabar-ghar, or the room that the bride and the groom would share, never has depictions of Rama and Sita in the murals painted in it, despite the deep-rooted connection of Mithila with the myth of Sita. Rather, there is a Shaivite influence in the Kohabar-ghar, with Shiva, the god of destruction and his consort, Parvati being depicted as they are considered the perfect holy couple, unlike Rama and Sita who were tragically separated after they were married. Hence, these paintings are not just aesthetical but very ceremonial and culturally relevant even in today's time. These depictions are mostly made by people from Brahmin and Karna Kayastha communities since most mythological and religious themes are illustrated by them as a part of the social caste construct.

The main source of Kachni style (monochrome line painting) of Madhubani painting is the courtyard painting or aripan. This style is still found to be thriving in Mithila in real spaces, whereas the Bharni style (subject filled with solid bright colors) evolved from the wall painting have confined mostly to the paper or canvas now. The Bharni style has been a lesser inclusive art form in Mithila, as most of the legends associated with marriage cannot be attributed to all the castes and classes of society in the region, whereas in Kachni style, economic activities of the region have been depicted in details for centuries. This form of painting can also be used for the anthropological research and studies. So, Kachni style has more variety and it has more demonstrative value of the Mithila region. It has also remained less affected by commercialization and other factors. Kachni is characteristically minimalistic and line work is its main feature, colors are also sparingly used in this style. Other styles of paintings are made by lower caste people, which are visually and stylistically different. One of these styles is called Godana, which literally means tattooing. Line work with monochromatic designs and motifs are the main characteristics of this style and mostly they portray daily and community-based activities in their paintings. It could even be debated as to whether these paintings can be considered to dwell within the grounds of Madhubani painting. It is important to note that motifs, usage of color, symbols, etc. all of them are traditionally variable from one community, caste, family, village, etc. to another. This variability thus creates different market spaces for each style. In the market, demand is created by multiple tastes and needs. For a particular consumer, a traditional mythological Ram-Sita portrayal made with Bharni style of Madhubani painting could be of more appeal. While, another consumer may be interested in Godana form of painting with symmetrical patterns. It is astounding how the commercial art sector allows different ideologies within the same art form to coexist and yet have separate identities.

\section{ARTISTIC IDENTITIES}

Artists like Jaishankar Lal Das 'Kamlesh' from Ranti follow the customary path of making Madhubani painting. Das, unlike many artists today, still paints using natural dyes that are locally sourced like the Plaash, Harshringar, Tilkor, Sikket, Peepal tree bark, etc. he explains how using natural dyes makes a painting unique. He says freshly acquired resources have to be used quickly since they oxidize and change the wanted hue for which it was derived. He also mentions how not all plants and flowers are available round the year, certain plants grow only in specific seasons and he has to ravage through forests and small trails to find them. Jaishankar Lal Das discussed how he tries to keep his work as traditional and intricate as possible. Small details like double lining using an old-fashioned kalam is important to him, he discussed how most commercial artists claim to be traditional and naturalistic but they often fail to be what they claim. He further explains that market compels you to resort to these tactics but if you are familiar with Madhubani painting, you can certainly differentiate between authentic and synthetic artworks. His focus of most paintings are the very established 
depictions of Indian mythology including scenes from the Ramayana, Mahabharata as well as flora and fauna including the iconic symbolisms of fishes, parrots, elephants, flowers, etc. on traditional mediums like cloth and paper.

Bipin Das, son of pioneer artist Mahasundari Devi and husband to artist Bibha Das also conveyed his ideas regarding the art scene in regards to Madhubani painting. His ideas are quite similar to those of Jaishankar Lal Das, he elucidates how these days, to the constant push by commercial forces and sometimes even government intervention, artists lose the sanctity of Madhubani painting. Young artists, who get into this field with the sole motivation of making a livelihood out of art, often are unaware of the rituals and purpose behind making Madhubani painting. He expressed his dissatisfaction for the paintings made on the Madhubani Railway Station. He says many of it is disrespectful and made in bad taste, for him this art form is sacred. He discussed how visual renderings of gods and goddesses are made near sewers and other dirty places in the name of beautification and hurts religious and cultural sentiments of the people of Mithila. He points out how it is especially important to be careful of art being created on such a huge platform; a huge responsibility comes with representing a culture and many artists fail to do so appropriately. For example, the paintings at the Railway Station show portrayals of a modern-day family, the paintings illustrate a modern household with technological advancements. The question that arises here is that what could be the motivation behind these illustrations? While purists consider these paintings to have been made in bad taste, the other motive to do so could have been to be relatable and applicable to the present. Perspectives are always multifaceted and very personal when it comes to the consumption of art.

Bipin Das expressed how he would work along his mother as a child, recalling her eye for detail. He mentioned the detailing of the ornaments in her paintings, and how he would often complain about how time consuming the process was. His mother would tell him that she had seen her grandmother wear ornaments like these, which he had not, Kumar explains. Art has, since the earliest times, reflected the "normal" of the artist. Folk art, in particular, is limited to a cultural or geographic space, but like any other form of art, it is not unsusceptible to evolution through time and generations. These variations are often subtle. For instance, we find fewer depictions of brides being carried on palanquins, the Doli as it is commonly known, in Madhubani paintings of the present day simply because it is a dying practice in the age of motor vehicles. Perhaps what brings about this evolution in folk art is also its detachment from permanence1. Paintings are made often, but they're not made to stand the test of time. The natural ingredients that go into the making of paints, pastes and powders wash off or pervade into the mud surface within days. Art lapses are not uncommon, even with the plethora of rituals carried out and festivals celebrated in Mithila. Old paintings dissolve after one ceremony and with the onset of another, they're made anew. With each new painting made, the worldly horizons of the artists gradually grow.

This picture changes with commercialization and as artist is distinguished from artisan [4]. When a folk artist turns the same ritual based art portable and sellable, they introduce it to permanence. More importantly, they elevate folk artistic evolution to a broader, popular culture influenced form. The artist tuned artisan now not only incorporates elements from their immediate surroundings, but the surroundings of their buyers. For instance, the modern artist Raja Ravi Verma's work had let to the onset of calendar art in India in the 19th century. Prints of Ravi Verma's original oil paintings were in circulation in the market, and his depictions of gods and goddesses are still popular in India today. Upon migrating to metropolitan cities, artists get a glimpse of how gods and goddesses are portrayed in paintings and prints outside their native villages in artforms they are not familiar with. Thus, they adopt the art themes popular among their buyers and try to replicate them in their traditional style. For example, deities like Ganesh are often depicted in Calendar art and the same themes are adopted by Madhubani painters. Additionally, Miniature paintings of Radha and Krishna, the lovers, have begun to be replicated as art catalogues can easily be purchased from museums and art galleries by artists. It is not uncommon to find paintings of Krishna playing the flute under a tree with Radha by his side.

A typical depiction is also of the Buddha in his meditating place, which can be found across modern art made with a range of art media. It is a common picture in urban homes and although Mithila is in close proximity to major Buddhist sites in India like Vaishali as well as Nalanda, Madhubani artists never incorporated Buddhist motifs in their art. Mithila painting has always been dominated by Hindu mythology, particularly by depictions of cultic gods. However, with commercialization and the influence of popular culture, one would be able to find Buddha made in the Madhubani style, sitting cross-legged on a raised platform, with the typical Gandharan Buddha hairdo. The painting that we came across was similar to the description given above, along with a Bharani background. It is easier to point out the modern influences in Mithila paintings like these, because even though they are Mithila paintings, they seem to belong to almost a completely different genre at the same time.

Apart from depictions of gods, we find day-to-day items converted into Madhubani motifs. There may be fewer depictions of the Doli, but there are certainly depictions of motor vehicles in the Madhubani paintings on the walls of the railway station in Mithila. Debit cards issued by the State Bank of India are illustrated with a Madhubani painting of a woman carrying modern shopping bags. The artist's audience now is the whole world, rather than the people of one district in northern Bihar. Therefore, as far as commercial folk art is concerned, nearly every object can be turned into a motif.

\section{CONVENTION AND MODERNITY}

It is important to understand the transition between the mediums of Madhubani Painting and how it defines the art form in the present times. When it started out in the domestic spaces on earthen surfaces as aripan and then later as murals, the tools and techniques were different. Hand, fingers, cotton swabs, brushes, etc. were used to paint on wall and ground, as a result the artworks that were created were bold, not as refine and intricate as modern age Madhubani paintings. When the medium switched to paper, cloth and other portable mediums, the patterns and stylistics changed. It became far more detailed, lining became important, and motifs were sharper 
among many other developments. While art became portable, it also became permanent. Art was now created to sustain forever. Traditionally, paintings were made and remade. They were not meant to last eternally. As seasons, occasions and necessities changed so did the art. Every time the homes would get a fresh coating of cow dung and mud, a new aripan and mural would be made. Each festival and custom would have a different rendering. Thus, traditionally art was transient, it was not permanent, bringing in the change by adding new elements and subjects to the art form. The artists observed that the finer and detailed the work was, the more it got commercialized, losing its essence and raw nature that came to the art form spontaneously. Now that considerable time of the undertaking of mainstreaming Madhubani Painting has gone by, connoisseurs have started noticing the missing fundamental elements of it; there is a new drive of going back to the basics. Be it the medium, subject or style. But we have seen a new revivalist trend setting in the market, since the meticulous versions and styles of Madhubani painting are getting redundant, some artists are going back to the simplicity of folk art. There are discourses on the subject. There are also efforts to collect masterpieces and archetypes of Madhubani painting and write the grammar of the art form. Many critics look at this as a regressive approach. People say change is inevitable and the same is true with Madhubani Painting too. But it has to take a safer path. Marketability is important to survive, but if the painting starts losing its context and the characteristics, it would be difficult to remain in the market for long.

Originally, there was a relationship between the artist and the audience. As it is folk art, the folks of a region related and associated themselves with the art. But, when the boundaries of folk art expand from its native space, its dynamic changes, especially when it becomes commercialized. Madhubani painting evolved as a painting done by women. Evolution of this art was a gendered space because this was not an economic activity till recent times. This artform was very domestic in nature and had not patronage whatsoever in recorded history. Men have mostly been associated with the patronized and monetized forms of art. When the same attributes were attached to Madhubani painting, we saw the change. Now it has attracted men too, who are painting, critiquing, marketing and bringing in 'change' to Madhubani painting. Portability brought fortunes for Madhubani painting; it is a well-known fact that Madhubani and surrounding areas have very low income generating economic activities- small farms, mango orchards and fisheries. Madhubani painting too became a kind of cottage industry for the region. It has provided a source of income to many families in the last five decades. There are many families that have migrated from the region to bigger cities in pursuit of monetizing this art form. The portability worked, but this is also now leading to a sense of disconnect from the native culture. Many of the artists are not connected anymore with their roots and so they lack the appreciation and the essence of the paintings they make. And, the fact is that migrated artists dominate most of the market space of this painting.

As other landlocked cultural regions, Mithila too had the tradition of long festivities on the occasions of marriage and related year-spread rituals. For every occasion there was an art-story which added color to the festivity and the rituals.
The canvas has been the inner and outer walls of mud homes of Mithila. Most of the paintings have evolved as a wall-art and Madhubani painting too is not an exception. Now that mud homes are being replaced by Pucca or concrete houses, Madhubani painting has actually lost its original canvas permanently. If one passes through Jitwarpur, Ranti or any other village famous for Madhubani painting, he or she cannot even get a hint of that art form and pass through.

\section{FROM THE AANGAN TO THE WORLD}

Another important canvas of Madhubani painting has been the courtyard, called Aangan in Mithila. The mud floor of the courtyard and also of the homes were painted as per the occasion. Kojagra, a ritual related with marriage and Chaurchan, the fourth moon, were the main occasions of making paintings on ground, Aripan or Alpana. Paintings drawn in white color with rice powder on the cow dung plastered ground surfaces of courtyards shined when moonlight illuminated them and visitors from the same village and nearby villages visited home after home appreciating the patterns and motifs of Alpana style of Madhubani painting. Courtyard paintings had a huge canvas, sometimes, spreading in thousand square feet and more. An interesting part of this painting was that it was done in one single day. Most of these were done by the young girls of the family, whereas the murals were mostly made by elderly women of the family assisted by the younger ones. The girls would discuss the designs and patterns to be included in the painting and would start making it in the afternoon and complete the same by sunset. While making Alpana, the girls would start from the four corners of the courtyard and would gradually come to the center complementing the style of each other. While painting they would also be found singing in chorus. This would also be the rehearsal of the songs that would be performed in the evening when visitors would come for the functions. As it is evident this painting had evolved in a particular environment, the courtyard of Mithila was normally a common open space of a joint family around which rooms were built. A joint family had a joint income and joint celebration and a battery of artists to paint or sing on any occasion without much of preparation. Now there are very few examples of joint families, as incomes are individualized and sourced differently. So, there are lesser courtyards and smaller canvases.

Commercialization of art does not merely adhere to the sellable factor of art; it is important to identify where and how art reaches an enterprising level. Madhubani Painting was initially pushed out of its geographical boundaries with the efforts of local administrators, foreign scholars, writers and academicians. Associations like the Master Craftsmen Association of Mithila of 1977 paved the way and acted like a structure for foundations, trusts and multiple forums that have been made for the commercialization of Madhubani painting. As a result, many award winning Madhubani artists like Mahasundari Devi, Ganga Devi and Sita Devi found their works making their way to various museums in India. Ganga Devi's critically acclaimed, "The Cycle of Life" is displayed in the National Crafts Museum in New Delhi; it is an example of a purely narrative based Maithil painting. There was much international recognition to be found 
following this. The Mithila Museum in Japan was set up by Tokio Hasegawa in the later part of the 20th century, housing hundreds of Maithil paintings both brought from India and made in Japan itself. Ganga Devi was among the painters invited to come and paint there, and one of her most striking works, "Train in India" is an avant-garde Maithil painting, showing men and women dressed in traditional Indian outfits travelling in train coaches being pulled by a steam engine, a mundane reality of her times. She does not forget the birds, leaves and flowers, thus incorporating the usual motifs of the native art of her village in a modern painting. Her American Series is also noteworthy for incorporating features of avant-gardism in Mithila art, particularly her "Ride in the Roller Coaster" which she made in late 1980s during her visit to the USA as a part of Festival of India's demonstration of indigenous Indian art in the United States[5].

\section{MAdhubani Painting In The MARKet}

These developments additionally provided the native artists a new exposure to an urban market. As a result, there were steady migrations under contractors, who usually hired artists to make paintings for them, supplying them further into the market. Thus, there was, in a way, a rise of intermediaries between artist and the buyers of their products. The platform through which a product including artworks becomes sellable is one of the most important factors of commercial art. In the context of Madhubani Painting, there are multiple forums and platforms through which it comes in contact with its consumers. In earlier times, local residents would contact the artists and ask them to make paintings for them and pay them accordingly. For example, artists in Rajnagar discuss how during the weddings, families would ask artists to create traditional, customary art for them and pay them a small amount of money. This relationship was built on mutual faith and understanding and money was not a driving force behind this. In today's time, the horizons of commercial art have broadened extensively; there are permanent markets for Madhubani painting, both physical and virtual. One of the greatest examples of this is Dilli Haat, which is a crafts bazaar and basically, a commercial center for artisans and artists across India. This is a permanent, open air market with numerous stalls set up by various artists and multiple Madhubani painting artists also sell their art here. Anju Mishra is a national awardee Madhubani artist hailing from a family of teachers, who currently rents a stall at Dilli to sell her paintings and the paintings of poorer artists who cannot afford to come to the capital city. Selling paintings in New Delhi is an expensive enterprise for poor artists - stalls in Dilli Haat can cost thousands of Indian Rupees for mere days and it only adds to the ever-increasing living costs. Other artists complained about the stalls being too cramped for the high amount of rent they are paying for it, the bamboo ceiling dripping and the stall itself getting flooded due to the monsoon rains. The obvious consequence is that artists increase the cost of their paintings. However, it affects the sale of the paintings and more often than not, they are forced to resort to low prices after much bargaining and accept the falling rates of profit. This is in stark contrast to the already recognised artists who get commissions in Mithila itself. They are able to save money on travel, rent and living in a metropolitan city and are thus sell their paintings at a lesser rate as compared to mobile artists, gaining more customers. Mobile artists like Anju Mishra have to, on the one hand, earn a living by selling their paintings outside Mithila and on the other hand, pay artists whose paintings they are selling along with theirs.

Another challenge for traditional artists is the new age technology. Silk sarees manufactured in the Bhagalpur district of Bihar can cost up to Rupees 5000 for an ordinary Madhubani artist who paints on cloth. Given the cost of the raw material and the painstakingly long process of painting silk, the prices of these sarees double and even triple by the time they make it to the market. However, for a silk weaver from Bhagalpur who is self-sufficient in producing yards of silk, the cost of the saree evidently lessens. The silk weaver easily gets Madhubani paintings printed on the saree at a minimal cost, posing a challenge to the Madhubani painters who paint the same thing by hand. The artists mention that governments hire contractors for public works, even for making giant Madhubani murals. The middlemen like the contractors who ultimately profit off of the grants that the government provides for the making of these murals. A chain like structure of commerce takes place where the contractors are often people who are from outside Madhubani and know nothing of the art itself. Because they have access to the market and enough sources to hire artists, they get absorbed in the commercial chain. More often than not, it is the artists who suffer as a result. The contractor may buy a dozen of their paintings at a low rate, but he sells them for double and triple the price in a market that they, as poor and unaware artists cannot reach. The artists barely get paid, but more than that, they have little say in the creation of the art itself. An artist may have the contract to paint a number of paintings in a set amount of time which turns the concept of ritualistic painting meaningless. The artist has a deadline to meet now and in the short amount of time, they rarely pay attention to symbolism in their art. It is true that young girls who paint and get paid are often able to support their families and get an education with their income, but after the contractor collects their paintings, there is little scope of being recognised for their individual skill. For the contractor and the market, they all have the same value. Thus, the Madhubani painters become anonymous, the only exceptions being in the case of, again, the "celebrity artists".

In the year 1999, Madhubani Painting was given the Geographical Indication Registry. The Geographical Indications of Goods (Registration and Protection) Act of 1999 (GI), "geographical indication", in relation to goods, means an indication which identifies such goods as agricultural goods, natural goods or manufactured goods as originating, or manufactured in the territory of a country, or a region or locality in that territory, where a given quality, reputation or other characteristic of such goods is essentially attributable to its geographical origin and in case where such goods are manufactured goods one of the activities of either the production or of processing or preparation of the goods concerned takes place in such territory, region or locality, as the case may be [6]. This act was a major breakthrough in terms of giving Madhubani painting recognition and identification as an art form that dwells within a geographical region, it was now considered as an art form of the people of 
Mithila and now they had intellectual property rights protecting their own culture. This ensured that monetization of Madhubani painting could not be done by the means of cultural appropriation by outsiders. But which section of artists benefit from this provision? Most artists do not even have the access to such endowments created by the government. It should be the governments' duty to approach artists and not the other way around. What we also notice is that funds and trusts made in the name of the development of Madhubani painting artists function like a sham.

\section{COMMERCIALIZATION AND AFTER}

The sphere under which Madhubani painting is developing today is multi-faceted. While it may seem like the government is trying to uplift the artists and creating a platform for this art form, it is essential to understand how Madhubani painting has been used to shape identities. There are other factors as well which pose different challenges for Madhubani painting. For instance, the entire city of Patna, the capital of Bihar is covered with Madhubani painting, almost every wall is filled with illustrations in the name of beautification and representation. It is as if the identity of Bihar is being synonymously equated with Madhubani Painting; but is this how the people of Bihar want to be identified? Madhubani Painting is a folk art, it is of the folks of Mithila and not the entire state of Bihar. It is losing its regional identity and charm through which it originally subsists. The artists who are deployed for these art works in cities are sometimes not even trained Madhubani painting artists. One can notice how starkly different an authentic Madhubani painting is from the paintings that are all over the city. Even the commissions made by the government are not well funded and planned. A niche identity based on a regional culture should not be imposed on an entire state. Every government has certain budget allocations for the promotion of art. Madhubani painting is a low hanging fruit for this purpose. On one hand it provides good number of 'job' opportunities for the people who pursue this form of art, but on the other hand we start losing the core of art. If one looks at the paintings carefully, most of them lack the basic characteristics of Madhubani painting and become very poor examples of the art form to be portrayed to the world. This approach is also not appreciable for the fact that resources of government are not evenly apportioned for other art forms of the region which may also lead to an unnecessary rivalry of the artists of different art forms. Plurality works better in the field of art.

What happens with this decision is that firstly, the art form does not resonate with the entirety of a population. Secondly, other art forms and cultural developments within the same state get ignored. Thirdly, the art form being promoted reaches a level of creative saturation and loses its charm.

\section{CONCLUSION}

Mithila was the home to four of the six Shad-Darshanas, which were schools of philosophy - Nyaya, Mimamsa, Vaisheshika, and Sankhya. While for the most part it remained unaffected by invasions in the ancient times, yet it was not at all passive or not in touch with global influences [7]. In fact, it was a center for scientific, religious, cultural and philosophical interactions. In a similar fashion, the folk culture of Mithila has developed with extremely thoughtful intentions, although it has largely developed self sustainably like most folk cultures. The beauty of Maithil folk culture is that it was and is still homogeneous, encapsulating complexities of the societies and communities.

Now when the region's culture has gone through a transition from being non-commercial to being a hub of commercialized art, there is a need for thoughtful and careful documentation of the characteristics of Madhubani painting so that the portability does not harm the very existence of the art form. There are some realities of this art form, which have to be accepted and delicately analyzed without being agitated. For example, there are elements of seclusion, which need to be accepted just as an element of art. There are many motifs and symbols, which can be explained only through the cultural practices of Mithila. Art forums and government bodies should commission some research proposals for such documentation. Apart from textual documentation, audio-video productions and putting them in public domains would be helpful in retaining the core aspects of Madhubani painting and educating the people about the actual customs and traditions behind it. The same should also be done for documenting the various methods of producing indigenous and organic colors that Madhubani painting is famous for. This may also lead to some kind of standardization process on an informal basis among the artists and their connoisseurs for better appreciation of traditional art. We are losing the doyens of Madhubani painting very fast as it has completed about five decades of the commercialization and portability of the art form. These initiatives and programs would help to preserve the zenith and core characteristics of Madhubani paintings forever. Change is inevitable and expression is the translation of human experiences, but it is important to make a sanctuary for an art form that has condensed generations worth of experience, narratives and culture.

\section{CONFLICT OF INTEREST}

The authors declare no conflict of interest.

\section{AUTHOR CONTRIBUTIONS}

Shreyasi Jha conducted the surveying and fieldwork process in Madhubani. Aqsa Ashraf analyzed secondary data and did the literature review. Both, Jha and Ashraf also went to Dilli Haat to interview artists. Jha and Ashraf both wrote the paper and approved the final version.

\section{ACKNOWLEDGMENT}

As students of history and appreciators of arts and aesthetics, Madhubani painting had held a special place in our hearts for a very long time. We were incredibly fortunate to get the opportunity to be able to analyze it academically and this paper was the result of a very long summer of writing, painting, and meeting artists and scholars. Our paper is still a research in progress, and we are immensely grateful to everyone who has helped to make this journey successful this far. To begin with, we would like to thank Shreyasi's father, Mr. Akhilesh Jha, for constantly guiding us academically and 
providing us insights into the culture of Mithila that are hard to come by anywhere else. We would like to thank our mothers, Mrs. Rashmita Jha and Ms. Rukhsana Khatoon, for being there for us on our worst days when we felt like the paper was going nowhere. Shreyasi's grandfather, Dr. Sitaram Jha 'Shyam' was a great help when we wanted to understand what makes Madhubani painting so unique. We thank Shreyasi's uncle, Mr. Awadhesh Jha for helping us connect and interact with artists in Bihar. We are thankful to Shreyasi's younger sister, Samiha and Aqsa's younger brother, Ismail, for giving us love and never stopping to make us laugh. Our teacher, Ms. Deeksha Bhardwaj picked out the most wonderful readings on Art History at the Lalit Kala Akademi library and always made time for us when we needed help. We couldn't be more grateful for all the help and guidance. We would also like to thank the Department of History, Gargi College, for providing us with an enriching environment to strive to become better scholars and never stop asking questions. We are grateful to Dr. Sanjay Manjul, Director of the Institute of Archaeology, for discussing with us the realities of the commercial spaces of this art and providing us nuanced details to help us understand the transition of Madhubani painting from a ritualistic to a commercialized form of art. Our gratitude goes out to $\mathrm{Mr}$. Bipin Das, Mr. Jaishankar Das, Mrs. Anju Mishra and all other Madhubani artists we met throughout our research in Mithila and New Delhi. Folk artforms disappear when people forget that culture is far by the greatest intangible heritage, and not to mention, a blessing. These artists inspired us every day and taught us that every artform is a treasure in itself. We were able to find a platform to make our research a success because of the International Journal of Culture and History's annual conference. We thank them for giving Shreyasi this opportunity to explore her roots like never before and represent her culture, and for giving Aqsa the opportunity to learn about a culture that she is so fond of in a way very few are able to. We would like to thank our friends, after all, we have the best of them. Lastly, we would like to thank each other for the hard work and the support when researching became too overwhelming.

\section{REFERENCES}

[1] The terms "Madhubani painting" and "Mithila painting" have been used interchangeably throughout the paper. Both connote the same artform.

[2] W. G. Archer, "Maithil painting," Marg, vol. 3, no. 3, pp. 24-33, July 1949.

[3] J. J. Chavda, "The narrative paintings of India's Jitwarpuri women," Woman's Art Journal, vol. 11, no. 1, pp. 26-28, 1990.

[4] E. Cohen, "The commercialization of ethnic crafts," Journal of Design History, vol. 2, no. 2/3, pp. 161-168, 1989.

[5] R. H. Davis, "From the wedding chamber to the museum: Relocating the ritual arts of Madhubani," in What's the Use of Art?: Asian Visual and Material Culture in Context, J. Mrazek and P. Morgan Ed. University of Hawai'i Press, 2008.

[6] India code: Digital repository of all central and state acts. [Online] Available:

https://indiacode.nic.in/handle/123456789/1981?view_type=browse

[7] A. Jha, "Mithila ki loksanskriti evam lok-kathayen (The folklore of Mithila)," Remadhav Publications, New Delhi, India, 2007.

Copyright $\odot 2020$ by the authors. This is an open access article distributed under the Creative Commons Attribution License which permits unrestricted use, distribution, and reproduction in any medium, provided the original work is properly cited (CC BY 4.0).

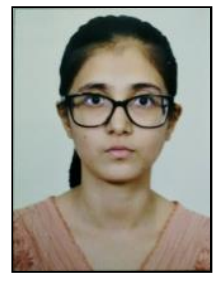

Aqsa Ashraf was born in New Delhi, India, on the $7^{\text {th }}$ of November, 1998. She is currently a third-year undergraduate student of History at Gargi College, affiliated to the University of Delhi.

She has previously interned under the Maharashtra State Archaeological Department and studied the Mesolithic petroglyphs that have been discovered along the Konkan Coast in India. She has also interned under the Art Conservation department at the Indira Gandhi National Centre for the Arts in New Delhi, India.

Ms. Ashraf was a part of the Fine Arts Society of Gargi College during the academic sessions of 2017-18 and 2018-19. She has been the part of the English Creative Writing society of Gargi College since the academic session of 2017-18. She is currently preparing to pursue a master's degree in art history and a career in fine arts and creative writing.

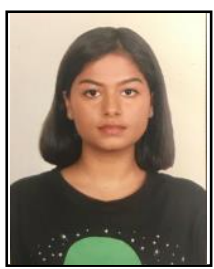

Shreyasi Jha was born in New Delhi, India, on the $21^{\text {st }}$ of November, 1999. She is currently a third-year undergraduate student of history at Gargi College, affiliated to the University of Delhi.

She has previously interned as an assistant curator at the Asia and Pacific Museum in Warsaw, Poland. Additionally, she has interned under the Maharashtra State Archaeological Department and studied the Mesolithic petroglyphs that have been discovered along the Konkan Coast in India. She has also interned under the Art Conservation Department at the Indira Gandhi National Centre for the Arts in New Delhi, India.

Ms. Jha is the vice-president of the United Nations Girl Up group Aamodini. She is currently preparing to pursue a master's degree in art history and archaeology. 